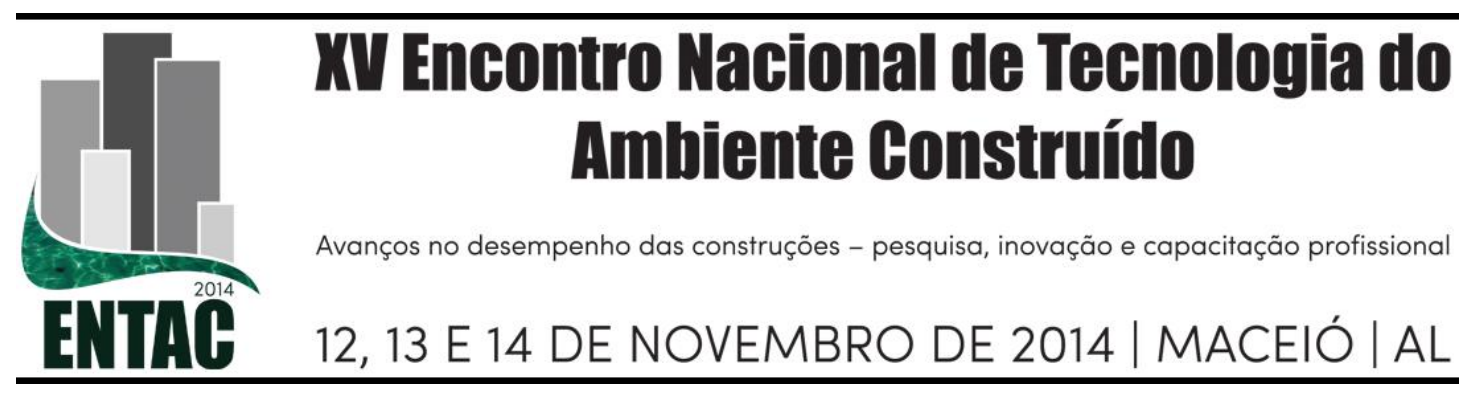

\title{
ANÁLISE DE DIFERENTES TIPOLOGIAS DE CONSTRUÇÃO EM CONCRETO E PVC
}

\author{
BRANDÃO, Laís (1); MELO, Karoline (2) \\ (1) Engenheira Civil, e-mail: laisscb@ hotmail.com, (2) Universidade Federal de Alagoas, e-mail: \\ melokarol@gmail.com
}

\begin{abstract}
RESUMO
O setor da construção civil no Brasil passou por algumas modificações com a abertura do mercado para produtos importados, normalmente de melhor qualidade. Para poder se tornarem mais competitivas, as empresas construtoras foram obrigadas a investir em produtos mais racionalizados e industrializados, como forma de reduzir as perdas geradas na obra. Este trabalho tem como objetivo analisar projetos e custos de diferentes tipologias construtivas do sistema construtivo em Concreto e PVC por meio de comparações com o sistema tradicional. Os resultados foram obtidos a partir da realização de um Trabalho de Conclusão de Curso de graduação em Engenharia Civil no ano de 2010, na cidade de Maceió-AL. Foram analisadas três diferentes tipologias construtivas: um protótipo de habitação popular, um posto de saúde e uma escola de educação infantil. O protótipo de habitação popular e a escola de educação infantil já haviam sido executados, no caso do posto de saúde a análise se deu em nível de projeto. Foram comparados projetos e orçamentos com o uso do sistema em Concreto e PVC e com a alvenaria tradicional de blocos cerâmicos para que se pudesse chegar às vantagens e desvantagens do novo sistema. Com a análise dos projetos pôde ser constatado que o sistema construtivo inovador gerou um acréscimo na área útil da edificação. Através dos comparativos dos orçamentos chegou-se a conclusão de que o custo de construção do sistema em concreto e PVC é consideravelmente mais elevado que o custo do sistema convencional. Porém deve ser analisado ainda se o custo quase inexistente com manutenção do sistema em PVC, não compensaria este custo inicial.
\end{abstract}

Palavras-chave: Sistemas construtivos, Inovação tecnológica, Concreto e PVC.

\begin{abstract}
The construction sector in Brazil gone through some changes with the opening of the market for imported products, usually of better quality. To become more competitive, construction companies have been forced to invest in more rationalized and industrial products, in order to reduce the losses generated in the work. This work aims to analyze projects and costs of different building typologies of the constructive system in Concrete and PVC by comparisons with the traditional system. The results were obtained from the realization of a Final Graduation Work in Civil Engineering Course in 2010 in the city of Maceio- $A L$. Three different building typologies were analyzed: a prototype of popular housing, a health center and a school for early childhood education. The prototype and the school had already been executed, in case of health center the analysis was done at the project. Projects and budgets were compared with the use of the system in concrete and PVC and with traditional masonry ceramic bricks so that they could get the advantages and disadvantages of the new system. With the analysis of projects could be found that the innovative construction system resulted in an increase in the floor area of the building. Through comparison of costs reached the conclusion that the cost of system construction and PVC in particular is considerably higher than the cost of the conventional system. But should still be analyzed the reduction of maintenance cost in concrete and PVC system.
\end{abstract}

Keywords: Constructive systems, Technologic innovation, Concrete and PVC. 


\section{INTRODUÇÃO}

Até o fim da década 70, a indústria da construção brasileira não apresentava nenhum programa de qualidade e, por esta razão, embora o Estado tivesse investido grandes cifras no setor, não se arriscavam inovações. Nas últimas décadas alguns passos foram dados, mas o setor ainda não conseguiu se igualar ao nível de eficiência, produtividade e qualidade de outros setores da indústria (NASCIMENTO; SANTOS, 2003).

Ainda que esteja ocorrendo industrialização de algumas técnicas construtivas e uma substituição do trabalho artesanal por sistemas construtivos mais mecanizados e bem organizados, a construção civil segue apresentando características antiquadas.

O objetivo principal deste trabalho é realizar uma análise crítica do sistema construtivo em concreto e PVC, a partir da avaliação de diferentes tipologias construtivas, indicando a viabilidade de se construir adotando-se este sistema.

O sistema construtivo composto de perfis modulares em PVC recheados com concreto representa uma tecnologia bem atual no mercado brasileiro, por isto o domínio de suas técnicas construtivas ainda é limitado e o uso restrito a poucas experiências (SOUZA, 2005).

O modelo proposto é modular, pois seus perfis já vêm de fábrica com determinada espessura, porém existem peças adaptadoras, que ajustam a parede em seu comprimento determinado em projeto.

Este sistema é composto por painéis de duplo encaixe, tipo macho-e-fêmea, ocos, em duas camadas de PVC (coextrudados), com diversas espessuras, armados e preenchidos com concreto no local (SILVA; KAWANO, 2009).

A utilização de novas tecnologias na construção civil, como a proposta, proporciona muitas vantagens se for bem utilizada e fruto de uma análise prévia. Porém, muitas inovações são inseridas sem que seja realizado um estudo de viabilidade e de desempenho do sistema estrutural. O que acaba resultando em uma série de problemas.

\section{REVISÃO BIBLIOGRÁFICA}

\subsection{Industrialização e Racionalização da Construção Civil}

A construção civil possui uma grande diferença se confrontada a outros setores da indústria: o produto não se desloca, matéria prima, mão-de-obra e equipamentos é que se deslocam até o local de aplicação. A indústria da construção está em situação oposta à indústria de montagem (eletrônica, automobilística), onde o processo é altamente mecanizado e as máquinas são rigidamente locadas na fábrica, seguindo a sequência produtiva. A falta de mecanização da indústria da construção gera uma baixa produtividade (MAUÉS, 1996).

Portanto, as empresas do ramo estão sendo forçadas a redefinirem suas estratégias, com o objetivo de incrementar a eficiência do método de operação, melhorando a qualidade e reduzindo custos (PICCHI, 1993).

A racionalização pode ser entendida como um processo que tem por objetivo a melhor utilização de todos os recursos que interferem na construção e deve ocorrer de forma dinâmica sendo aprimorada sistematicamente (LICHTENSTEIN, 1987).

De acordo com Maués (1996), a racionalização no Brasil se dá sob várias vertentes, dentre elas destacam-se o desenvolvimento de sistemas construtivos inovadores, a 
implantação de mudanças de forma a aprimorar o processo convencional e o uso cada vez mais frequente de sistemas pré-fabricados.

Dentre os sistemas construtivos que contemplam aspectos relacionados à racionalização e pré-fabricação, destaca-se, no presente trabalho, o método em concreto e PVC.

\subsection{O sistema construtivo em Concreto e PVC}

O sistema construtivo em concreto e PVC surgiu inicialmente no Canadá e consiste em painéis de PVC preenchidos com concreto e aço estrutural. Os painéis em PVC servem de fôrma, revestimento e ajudam na estruturação do conjunto. Foi desenvolvido para projetar e construir de forma simples e industrializada vários tipos de edificações. É um sistema modular, composto por painéis verticais que se encaixam por guias (machofêmea) (SILVA; KAWANO, 2009).

As paredes, tanto na face interna como na externa, não necessitam de revestimentos, pinturas ou tratamentos. Porém, qualquer tipo de pintura ou outro recobrimento pode ser colocado sobre os perfis mesmo após anos da montagem inicial (ROYAL, 2008).

Ainda segundo a Royal (2008), as instalações elétricas e hidráulicas são convencionais e sempre no sentido vertical. Entrando pela parte superior do pé direito ou pela inferior (base de concreto), os tubos tem um curso percorrido dentro dos painéis, favorecendo a localização dos diferentes circuitos. Trata-se de um processo industrializado, organizado em cinco etapas: infraestrutura, superestrutura, cobertura, acabamentos e instalações (SOUZA, 2005).

O concreto utilizado para o preenchimento das paredes deve ser fluido e, preferencialmente, autoadensável. A altura máxima de uma parede utilizando o sistema em concreto e PVC, assim como de uma parede em concreto tradicional, depende da altura máxima de queda do concreto.

\section{MATERIAIS E MÉTODOS}

\subsection{Objetos de estudo}

Os objetos de análise do presente trabalho foram: um protótipo de habitação popular, um posto de saúde e uma escola.

O protótipo de habitação popular foi construído em julho de 2006 na sede do Sistema Nacional de Aprendizagem Industrial de Alagoas (SENAI-AL) como um estudo da Caixa Econômica Federal para a análise de viabilidade da construção de casas populares utilizando o sistema construtivo em concreto e PVC. O protótipo estudado possui dois quartos, banheiro, cozinha e sala de estar/jantar em uma área aproximada de $30 \mathrm{~m}^{2}$. As paredes não possuem revestimento assim como o piso, que é cimentado liso. As esquadrias são em madeira e a cobertura é tradicional com estrutura de madeira e telhas cerâmicas, a casa não possui forro ou laje de cobertura nem vigas de concreto. A espessura das paredes é de $75 \mathrm{~mm}$.

O posto de saúde é um projeto da Secretaria Municipal de Saúde de Maceió, que não havia sido executado. Existem somente os projetos arquitetônicos, com locação dos pontos elétricos e hidrossanitários, orçamento e especificações. A área construída em projeto é de $673,66 \mathrm{~m}^{2}$. O piso especificado é em granilite e o teto é em laje de concreto pintada com tinta acrílica, a cobertura em estrutura de madeira com telhas de fibrocimento e janelas em alumínio e portas em madeira e ferro. Na modulação do projeto foram utilizados perfis de $140 \mathrm{~mm}$, e a espessura da parede é de $100 \mathrm{~mm}$. 
A escola estudada pertence à rede Municipal e está situada do bairro do Pontal em Maceió, inaugurada pela Secretaria de Educação do município em 18 de maio de 2009. A escola possui área de $871,46 \mathrm{~m}^{2}$ e a espessura das paredes com o uso do sistema em Concreto e PVC é de $100 \mathrm{~mm}$.

\subsection{Levantamento de dados}

A coleta de dados ocorreu junto aos órgãos responsáveis por cada tipologia construtiva. Foram coletados documentos como orçamentos, projetos e especificações existentes no órgão, além de qualquer outra informação que pudesse ser fornecida sobre o sistema construtivo. Esta etapa incluiu visitas aos prédios, com registro fotográfico e levantamento documental.

Os documentos fornecidos referentes ao posto de saúde foram: projeto arquitetônico completo, em alvenaria; projeto de modulação do sistema construtivo em Concreto e PVC e os orçamentos dos dois sistemas. Quanto ao protótipo de habitação popular foram obtidos todos os projetos, inclusive os de instalações e montagem do sistema construtivo, orçamento e memorial descritivo. Os dados referentes ao protótipo já contemplam a construção no sistema construtivo em Concreto e PVC. Com relação à escola, dentre os documentos cedidos se encontram o projeto arquitetônico e o orçamento da construção com a utilização do sistema em Concreto e PVC.

\subsection{Análise do sistema construtivo em Concreto e PVC}

Para analisar a viabilidade do Concreto e PVC, foi feito um comparativo entre este sistema construtivo e a alvenaria de blocos cerâmicos, para cada tipologia estudada. Assim, procurou-se uniformizar os documentos do mesmo sistema construtivo e também os documentos dos dois sistemas analisados para uma mesma edificação. A partir desta observação, de acordo com a necessidade de cada objeto de análise, foram refeitos projetos e orçamentos.

Para os dados referentes ao protótipo de habitação popular observou-se que o projeto arquitetônico contemplava o sistema em Concreto e PVC com modulação de $75 \mathrm{~mm}$ e com espessuras de paredes de $75 \mathrm{~mm}$. O projeto foi então refeito para a mesma construção em alvenaria convencional, aumentando-se a espessura da parede de $75 \mathrm{~mm}$ para $150 \mathrm{~mm}$. As paredes externas foram acrescidas de $75 \mathrm{~mm}$ para o interior, tendo em vista que nem sempre existirá a possibilidade de aumentar a área construída devido a falta de espaço no terreno. Já para as paredes internas, foi feita uma divisão igualitária destes $75 \mathrm{~mm}$ adicionais para os dois lados da divisória. Em seguida foi feita uma atualização do orçamento existente, de 2006 para 2010, e elaboração de um orçamento para o sistema construtivo tradicional.

No caso da escola, adotou-se esta mesma metodologia de análise, porém a espessura da parede encontrada na modulação do projeto é de $100 \mathrm{~mm}$, de modo que o projeto modulado teve a espessura de suas paredes acrescidas de $50 \mathrm{~mm}$, a fim de serem atingidos os $150 \mathrm{~mm}$ empregados no sistema convencional. Para as paredes externas esses $50 \mathrm{~mm}$ foram adicionados para o interior da edificação e para as internas dividiuse $25 \mathrm{~mm}$ para cada face da parede.

Com relação ao posto de saúde, percebeu-se que com a modulação do projeto arquitetônico, ocorreram mudanças nos comprimentos das paredes, o que modifica todos os ambientes do projeto e suas respectivas áreas. O projeto modulado do posto de saúde possui uma área de $822,57 \mathrm{~m}^{2}$ enquanto que o projeto arquitetônico, em alvenaria de blocos cerâmicos, apresenta uma área total de $836,87 \mathrm{~m}^{2}$. Com esta observação, 
verificou-se a necessidade de utilização de uma outra forma de análise. Portanto, foi mantida a comparação dos projetos originais, pois a mudança das áreas aconteceu em consequência da modulação, mas, além disso, a partir do projeto modulado foi elaborado um novo projeto em alvenaria convencional, aumentando-se a espessura das paredes. Esta segunda abordagem foi feita para manter o padrão comparativo adotado nos demais projetos.

Os orçamentos das diversas construções, quando existentes, foram atualizados para os preços praticados em 2010, quando da realização deste trabalho, e foram feitos os orçamentos decorrentes dos novos projetos elaborados.

\section{RESULTADOS E DISCUSSÕES}

$\mathrm{O}$ artigo deverá ser estruturado da seguinte forma:

\subsection{Protótipo de habitação popular}

Para representar as diferenças de concepção de projeto na Tabela 1 estão apresentadas as variações das áreas e perímetros.

Tabela 1 - Áreas e perímetros internos da casa alagoana e percentual de acréscimo com a utilização do sistema em Concreto e PVC

\begin{tabular}{c|c|c|c|c|c|c|c|c}
\hline \multirow{2}{*}{ Local } & \multicolumn{2}{|c|}{ Convencional } & \multicolumn{2}{c|}{ Concreto e PVC } & \multicolumn{2}{c|}{ Acréscimo } & \multicolumn{2}{c}{ Acréscimo $(\%)$} \\
\cline { 2 - 9 } & $\mathrm{A}\left(\mathrm{m}^{2}\right)$ & $\mathrm{P}(\mathrm{m})$ & $\mathrm{A}\left(\mathrm{m}^{2}\right)$ & $\mathrm{P}(\mathrm{m})$ & $\mathrm{A}\left(\mathrm{m}^{2}\right)$ & $\mathrm{P}(\mathrm{m})$ & $\mathrm{A}\left(\mathrm{m}^{2}\right)$ & $\mathrm{P}(\mathrm{m})$ \\
\hline $\begin{array}{c}\text { Quarto } \\
\text { maior }\end{array}$ & 6,96 & 10,66 & 7,57 & 11,11 & 0,61 & 0,45 & $8,76 \%$ & $4,22 \%$ \\
\hline $\begin{array}{c}\text { Quarto } \\
\text { menor }\end{array}$ & 5,75 & 9,60 & 6,30 & 10,05 & 0,55 & 0,45 & $9,57 \%$ & $4,69 \%$ \\
\hline W.C.B. & 1,69 & 5,33 & 1,94 & 5,70 & 0,25 & 0,37 & $14,79 \%$ & $6,94 \%$ \\
\hline Estar/Jantar & 8,30 & 12,44 & 8,95 & 12,89 & 0,65 & 0,45 & $7,83 \%$ & $3,62 \%$ \\
\hline Cozinha & 2,54 & 6,84 & 3,00 & 7,21 & 0,46 & 0,37 & $18,11 \%$ & $5,41 \%$ \\
\hline TOTAL & 25,24 & 44,87 & 27,76 & 46,96 & 2,52 & 2,09 & $9,98 \%$ & $4,66 \%$ \\
\hline
\end{tabular}

Fonte: Autor

Devido a uma diminuição de $50 \%$ da espessura da parede com a utilização do sistema inovador, houve um acréscimo de área de aproximadamente $10 \%$ em relação ao sistema tradicional. Houve também um aumento de 4,66\% no perímetro total da construção.

Percebe-se que o ganho percentual de área é inversamente proporcional ao tamanho do ambiente. Portanto, o menor ambiente (banheiro) teve o maior acréscimo percentual de área enquanto que a sala de estar/jantar teve o menor.

O ganho de área total chega a $2,52 \mathrm{~m}^{2}$, o equivalente a área da cozinha no projeto do sistema tradicional. Vale salientar que esta área adicional é diluída em todos ambientes, o que proporciona uma melhor comodidade para os moradores.

Com relação ao orçamento, foram observadas variações nas etapas de supra estrutura, revestimentos e pintura, as quais estão apresentadas na Tabela 2. Nesta tabela conta também o custo total da obra nos dois sistemas. 
Tabela 2 - Comparativo de custos para o protótipo de habitação popular

\begin{tabular}{c|c|c}
\hline \multirow{2}{*}{ Item do orçamento } & \multicolumn{2}{|c}{ Preço total (R\$) } \\
\cline { 2 - 3 } & Convencional & Concreto e PVC \\
\hline Supra estrutura & $1.671,82$ & $8.382,36$ \\
\hline Revestimentos & $1.755,15$ & - \\
\hline Pintura & 851,84 & 134,66 \\
\hline Custo total da obra & $14.859,90$ & $18.963,45$ \\
\hline Fonte: Autor
\end{tabular}

Observa-se um aumento no custo total do empreendimento de $\mathrm{R} \$ 4.103,55$ com o uso do sistema em Concreto e PVC. Este valor corresponde a aproximadamente $30 \%$ do custo da construção convencional.

No item supra estrutura houve um aumento de $\mathrm{R} \$ 6.710,54$, valor equivalente ao preço dos serviços de fornecimento e montagem dos perfis em PVC que é de R $\$ 6.392,47$.

Como no sistema em PVC não existe a necessidade de colocação de revestimentos, o custo desta etapa, que é de $\mathrm{R} \$ 1.755,15$, no sistema tradicional, é absorvido. Isto porque as paredes do sistema convencional recebem chapisco, emboço, reboco, pintura e revestimento cerâmico, o que acaba diminuindo um pouco a diferença de custo das estruturas.

Sabendo que a área construída do protótipo da habitação popular é de $30,12 \mathrm{~m}^{2}$, dividindo-se os custos totais de cada orçamento por este valor, chegamos ao custo de construção por metro quadrado. Para o sistema construtivo tradicional o preço do metro quadrado de construção é de $\mathrm{R} \$ 493,36$. Já para o sistema construtivo em Concreto e PVC esse preço chega a R \$629,60. Para uma habitação popular, esta diferença de custo de um sistema para o outro é significativa.

\subsection{Posto de saúde}

No caso do posto de saúde foram realizadas duas comparações: uma do projeto arquitetônico original com o projeto modulado e outra do projeto modulado com o projeto arquitetônico feito a partir dele para alvenaria convencional. Na primeira análise houve um acréscimo de $12,09 \mathrm{~m}^{2}$, que corresponde a $1,87 \%$ da área, e no perímetro o acréscimo foi de $1,95 \mathrm{~m}$ ou $0,25 \%$.

As áreas de alguns cômodos diminuíram, enquanto que as de outros aumentaram, o que se deve ao fato de que as paredes tiveram que ser adaptadas ao comprimento dos módulos, que era de $140 \mathrm{~mm}$. Um grande problema deste fato é que, em projetos tão específicos como este, a área de determinados ambientes é pré-determinada e não pode ser alterada. Observou-se ainda que os menores ambientes chegaram a ter quase $30 \%$ de sua área aumentada, enquanto que outros tiveram sua área reduzida em $10 \%$. Percebeuse uma necessidade de que o projeto arquitetônico seja executado desde o início seguindo a modulação. Desta forma são evitados retrabalhos e surpresas com a alteração das dimensões dos cômodos.

Comparando-se agora os dois sistemas construtivos na situação em que a partir do projeto modulado foi elaborado o projeto em alvenaria convencional, foram observados ganhos de áreas em todos os ambientes. O acréscimo total de área com o uso desta 
metodologia foi de $2,80 \%$, o que correspondente a $17,89 \mathrm{~m}^{2}$, mas ainda não chegou a ser tão significativo quanto no protótipo. Apesar de o acréscimo de área ser pequeno em proporção, ainda é maior que a área de alguns ambientes, como a sala de agentes de PSF ou o arquivo.

O sistema utilizado apresenta vantagens na concepção do seu projeto na medida em que pode gerar um aumento na área útil, tornando o ambiente mais confortável para os servidores da saúde, que tem o posto como o seu local de trabalho, e para os pacientes, que vão em busca de tratamento e esperam que o local tenha melhores condições de atendimento.

A partir da segunda metodologia de comparação dos projetos, foi feita a análise de custos. Neste caso, as etapas do orçamento destacadas para foram: supra estrutura, alvenaria e complementares, revestimentos e pintura, conforme a Tabela 3.

Tabela 3 - Comparativo de custos para o posto de saúde

\begin{tabular}{c|c|c}
\hline \multirow{2}{*}{ Item do orçamento } & \multicolumn{2}{|c}{ Preço total (R\$) } \\
\cline { 2 - 3 } & Convencional & Concreto e PVC \\
\hline Supra estrutura & $58.542,58$ & $296.280,13$ \\
\hline Alvenaria & $38.045,37$ & 33,92 \\
\hline Revestimentos & $59.009,46$ & - \\
\hline Pintura & $34.232,18$ & $7.934,49$ \\
\hline Custo total da obra & $563.820,37$ & $638.851,89$ \\
\hline
\end{tabular}

Fonte: Autor

Pela comparação dos orçamentos do posto de saúde percebe-se uma mudança de custo no item supra estrutura de $\mathrm{R} \$ 58.542,58$ no projeto convencional para $\mathrm{R} \$ 296.280,13$ no projeto em Concreto e PVC. Porém o custo com alvenaria e complementares passa de $\mathrm{R} \$ 38.045,37$ para $\mathrm{R} \$ 33,92$, o custo com revestimentos corresponde que era de RS 59.009,46 passa a ser zero e o custo de pintura do sistema convencional, R\$ $34.232,18$, é reduzido para $\mathrm{R} \$ 7.934,49$. Os preços de custo total dos orçamentos são de $\mathrm{R} \$ 563.820,37$ para o sistema tradicional e de $\mathrm{R} \$ 638.859,89$ para o sistema em Concreto e PVC. O item que torna o sistema em Concreto e PVC R $\$ 75.031,52$ mais caro, como já esperado, é a supra estrutura.

Dividindo-se o custo pela área construída é obtido um valor de $\mathrm{R} \$ 754,51$ por metro quadrado com o uso do sistema em Concreto e PVC, enquanto que com o sistema convencional este custo é de R $\$ 655,90$ por metro quadrado. Ao compararem-se estes valores com os do protótipo de habitação popular ( $\mathrm{R} \$ 629,60 / \mathrm{m}^{2}$ para o sistema em PVC e R $\$ 493,36 / \mathrm{m}^{2}$ para o sistema em alvenaria), nota-se que o custo por metro quadrado da construção com perfis de PVC preenchidos com concreto é mais barato para o protótipo. Porém, a diferença entre os valores dos dois sistemas é menor no posto de saúde - $\mathrm{R} \$ 88,61$ em relação ao protótipo - $\mathrm{R} \$ 136,24$.

\subsection{Escola}

O ganho em área com a utilização do sistema em PVC para a escola foi de $24 \mathrm{~m}^{2}$, o correspondente a 4,58\% de aumento em relação ao sistema construtivo tradicional. Um resultado bastante satisfatório ao se considerar a área da edificação. 
$\mathrm{O}$ ambiente que obteve o maior acréscimo percentual de área foi a sala do arquivo, com $13,17 \%$, e o menor foi a sala do maternal com 2,12\%. Mais uma vez, notou-se que quanto menor a sala, maior o seu percentual de acréscimo. Porém, a menor sala, o Almoxarifado, devido a metodologia utilizada e a sua localização em projeto, não apresentou o maior ganho de área.

Mais uma vez, foi encontrado, com relação ao projeto, um melhor resultado do sistema inovador em contrapartida ao sistema tradicional. O aumento de $24 \mathrm{~m}^{2}$ no projeto equipara-se ao refeitório da escola com o uso das paredes de alvenaria.

Quanto ao orçamento, para a escola em Concreto e PVC foram estudados: supra estrutura, revestimentos e pintura (Tabela 4).

Tabela 4 - Comparativo de custos para o posto de saúde

\begin{tabular}{c|c|c}
\hline \multirow{2}{*}{ Item do orçamento } & \multicolumn{2}{|c}{ Preço total (R\$) } \\
\cline { 2 - 3 } & Convencional & Concreto e PVC \\
\hline Supra estrutura & $50.786,55$ & $236.065,01$ \\
\hline Revestimentos & $48.543,75$ & - \\
\hline Pintura & $58.615,90$ & $5.196,13$ \\
\hline Custo total da obra & $598.744,15$ & $730.602,84$ \\
\hline
\end{tabular}

Fonte: Autor

Para a construção em alvenaria o custo total é de $\mathrm{R} \$ 598.744,15$, com a utilização do sistema em Concreto e PVC este valor sobe para R\$ 730.612,84 uma diferença de $\mathrm{R} \$ 131.858,69$. Novamente, o custo alto da estrutura em Concreto e PVC foi um pouco reduzido pelos revestimentos e pinturas.

Os custos com a estrutura foram $\mathrm{R} \$ 50.786,55$ no sistema tradicional e $\mathrm{R} \$ 236.065,01$ para o sistema em Concreto e PVC. Com o uso do sistema tradicional existe uma diferença nos valores de revestimento e pintura juntos de $\mathrm{R} \$ 101.963,52$.

Como a área construída é de $846,71 \mathrm{~m}^{2}$, chega-se a um custo por área de construção de $\mathrm{R} \$ 862,87 / \mathrm{m}^{2}$ com o uso do sistema inovador, enquanto que o metro quadrado do sistema construtivo convencional vale $\mathrm{R} \$ 707,14$.

\section{CONCLUSÕES}

Os resultados encontrados mostraram que a utilização do sistema construtivo em Concreto e PVC em substituição ao sistema tradicional em alvenaria de blocos cerâmicos proporciona um ganho significativo de área em projeto. Porém o custo de construção pode ser um empecilho na seleção do sistema construtivo, tendo em vista que o sistema em Concreto e PVC é, em média, cerca de $30 \%$ mais caro que o sistema convencional.

Mesmo sem a necessidade do uso de revestimentos no sistema em Concreto e PVC, ainda existe uma variação muito grande do custo inicial da construção. Um fator determinante neste quesito é que os perfis de PVC, não são fabricados no país, o que eleva o seu custo devido ao processo de importação. 
Apesar do alto custo inicial, o custo de manutenção do sistema em Concreto e PVC é quase nulo. Em uma cidade com alto grau de agressividade ambiental, como Maceió (devido a altos níveis de umidade e proximidade do mar), as estruturas convencionais estão sempre sofrendo com patologias, necessitando de reparos constantes. Para uma verificação exata de qual sistema proporciona uma melhor economia é necessária uma análise mais aprofundada de custos de manutenção de edificações.

\section{REFERÊNCIAS}

LICHTENSTEIN, N.B. Formulação de modelo para o dimensionamento do sistema de transporte em canteiro de obras de edifícios de múltiplos andares. 1987. 268p. Tese (Doutorado) - Escola Politécnica, Universidade de São Paulo, São Paulo.

MAUÉS, L.M.F. Metodologia de organização interna e melhoria do processo produtivo em centrais de montagens de componentes: um estudo de caso. 1996. Dissertação (Mestrado em Engenharia) - Universidade Federal de Santa Catarina, Florianópolis.

NASCIMENTO, L.A.; SANTOS, E.T. A indústria da construção na era da informação. Revista Ambiente construído, v. 3, n. 1, p. 69-81, 2003.

PICCHI, F.A. Sistemas da qualidade: uso em empresas de construção de edifícios. 1993. Tese (Doutorado em Engenharia de Construção Civil e Urbana) - Universidade de São Paulo, São Paulo.

ROYAL do Brasil Technologies S.A. Manual de Montagem do Sistema RBS-64. Rio Grande do Sul: Royal do Brasil Technologies S.A., 2008.

SILVA, F. B.; KAWANO, F. A. Paredes estruturais de painéis de PVC preenchidos com concreto armado. Téchne. Ed 152. Novembro 2009. Disponível em: $<$ http://www.revistatechne.com.br/engenharia-civil/152/paredes-estruturais-de-paineis-de-PVCpreenchidos-com-concreto-armado-156966-1.asp>. Acesso em: 18 de junho de 2010.

SOUZA, S. R. Elementos de análise para gestão de processos e desempenho de produtos em sistemas construtivos: estudo de caso com sistemas que adotam perfis auto-encaixáveis de PVC e concreto. 2005. Dissertação (Mestrado Profissional em Engenharia) - Universidade Federal do Rio Grande do Sul, Porto Alegre. 